This is the final peer-reviewed accepted manuscript of: Valda Rondelli, Camilla Casazza, Roberta Martelli, Tractor rollover fatalities, analyzing accident scenario which has been published in final form in Journal of Safety Research Volume 67, December 2018, Pages 99-106

The final published version is available online at:

https://doi.org/10.1016/j.jsr.2018.09.015

(C) 2018 Elsevier. This manuscript version is made available under the Creative Commons AttributionNonCommercial-NoDerivs (CC BY-NC-ND) 4.0 International License (http://creativecommons.org/licenses/by-nc-nd/4.0/)

\title{
Tractor rollover fatalities, analyzing accident scenario
}

\author{
Valda Rondelli, * Camilla Casazza, Roberta Martelli \\ Department of Agricultural and Food Sciences, University of Bologna, Italy
}

Keywords:

Accidents database

Tractor safety, driver restrain system

Fatal accidents

ROPS

Work-related deaths

\begin{abstract}
A B S T R A C T
Introduction: In many countries, traditional data sources for collecting injuries of workers covered by compulsory 16 accident insurance have recently been integrated by new observatories whose results may differ. A comparative 17 analysis of the Italian data collection systems related to fatal tractor accidents in agriculture was performed focus- 18 ing on tractor rollover fatalities with the aim of analyzing the accident scenario. Method: Data from the Opera- 19 tional Archives of the Italian Workers Compensation Authority (INAIL), which collects injuries of workers 20 covered by compulsory accident insurance and those of the National Surveillance System (INAIL_ASL), which 21 provides narrative text reports of work-related fatal accidents have been analyzed and compared to the informa- 22 tion collected by the INAIL Observatory. The INAL Observatory was recently set up to complement the collection 23 of fatal accidents involving agricultural machinery. Italian data were then compared to data available at an inter- 24 national level. Fatal tractor accidents vary considerably with respect to fatal accidents in agriculture, being 10.625 and $43.7 \%$ for the Operational Archives and Surveillance System, respectively. National Surveillance System re- 26 cords, implemented with narrative texts allowed the accident scenario to be defined. Results: $71.7 \%$ of fatal 27 tractor-related accidents refer to non-ROPS equipped vehicles and of these, 26.5\% involved machines originally 28 mounted with a ROPS that had been removed or was inoperative in the folded-down position during the rollover 29 event. Just one fatal event from a collapsed ROPS on the overturned tractor was recorded. It is interesting that 30 $16.6 \%$ of fatal accidents involved a clear environmental factor. Practical application: A campaign to train tractor 31 drivers on the correct use of the combination ROPS and seatbelt can contribute to decreasing rollover events 32 with fatal outcomes. Contemporarily a strict requirement to install ROPS and a seatbelt on tractors, combined 33 to an official inspection at the farm level, can increase the chance of survival in a rollover accident. 34
\end{abstract}

\section{Introduction}

Tractors are considered the leading cause of agricultural workrelated fatalities in many industrialized countries (Day, Rechnitzer, \& Lough, 2004; Myers, 2010; Reynolds \& Groves, 2000; Sanderson et al., 2006) and rollovers frequently account for more than $50 \%$ of tractor deaths (Jawa et al., 2013; Marshall, Clarke, Langley, \& Cryer, 1996; Myers et al., 1998; Springfeldt, 1996; Springfeldt, Thorson, \& Lee, 1998). Indeed tractors are particularly subject to rollover because of their high center of gravity, exposure to considerable external loads, large torque outputs, sloping or uneven ground (Guzzomi, Rondelli, Guarnieri, Molari, \& Molari, 2009).

Over the years, research studies on tractor rollover have been welldocumented (Arndt, 1971; Myers, 2000; Springfeldt et al., 1998; Tinc, Ayers, May, Purschwitz, \& Sorensen, 2015). After the pioneer work of using safety education to preventing tractor rollover, the innovative tractor design approach in the 1950s was the mounting of a passive

\footnotetext{
* Corresponding author at: Department of Agricultural and Food Sciences, University of Bologna, Viale Fanin, 50, 40127 Bologna, Italy.

E-mail address: valda.rondelli@unibo.it (V. Rondelli).
}

Rollover Protective Structure (ROPS), to provide the driver with a clear- 62 ance zone during a rollover accident (Fig. 1). The ROPS solution has 63 since been adopted worldwide and ROPS testing procedures have 64 been issued (Harald \& Moberg, 1973). The effectiveness of ROPS in 65 preventing rollover fatalities has been widely demonstrated 66 (Springfeldt, 1996; Reynolds \& Groves, 2000) and since 1974 official 67 rules have made ROPS compulsory for the type-approval of wheeled 68 agricultural and forestry tractors in Europe (European Commission, EC 69 Directive 1974/150).

A clear safety complement to ROPS in injury prevention during a 71 tractor rollover event was demonstrated to be the fitment of a driver 72 restraint system, such as a seatbelt (Reynolds \& Groves, 2000; Myers 73 \& Pana-Cryan, 2000; Molari \& Rondelli, 2007). In Europe, it has been 74 compulsory to fit new tractors with seatbelts since 2005 (European 75 Commission, EC Directive 1974/150, EC Directive 2005/67); while the 76 requirement for the in use tractors in Italy has been in force since 77 2008 (Legislative Decree 81/2008). Nonetheless, even if the introduc- 78 tion of ROPS and driver seatbelts is now well consolidated all around 79 the world, fatalities associated with farm tractors continue to be a seri- 80 ous occupational hazard (Reynolds \& Groves, 2000; Bunn, Slavova, \& 81 Hall, 2008; Mayrhofer, Quendler, \& Boxberger, 2014). 

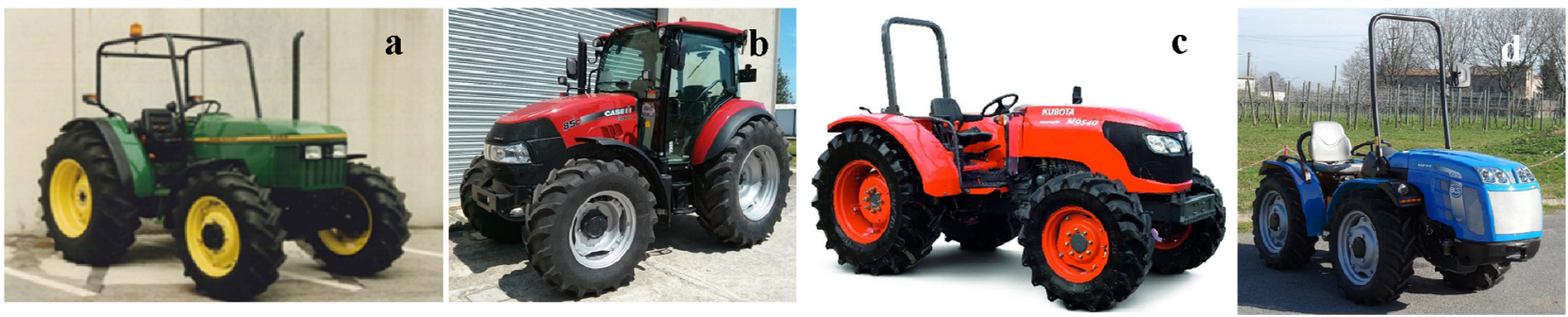

Fig. 1. Tractor ROPSs; (a) four post frame, (b) cab, (c) rear two post, (d) front foldable two post.

An analysis of the circumstances leading to tractor accidents could help in defining appropriate measures to prevent injuries and fatalities, and would provide information on the incidence of rollover and effectiveness of the ROPS protection. A statistical evaluation of tractor accident data is essential to develop prevention policies in agriculture. In many European countries, the reporting systems for work-related accidents insufficiently describe circumstances and causes of accidents, due mainly to the delay in acquiring information and lack of specific details. As a consequence, comparing data from different countries is rather difficult and often inappropriate because of the different approach in accident survey methods. In 1990, to harmonize countries data, the European Statistics on Accidents at Work (ESAW) was launched. However, tractor rollover accidents are not clearly specified in the ESAW approach; similarly, the additional circumstances that help in understanding the details of the accident, such as the presence of safety systems as ROPS and seatbelts, are not specified. To obtain more information on accident scenarios, Kogler, Quendler, and Boxberger (2015) suggested adopting the narrative text analysis approach as an accident reporting system.

In many countries, workers compensation archives include all types of injuries in agriculture if related to workers covered by compulsory accident insurance, but exclude the many self-employed workers, unpaid family members, or retirees who frequently work on farms. To overcome this limitation, national surveillance systems have been organized in many countries, together with report systems, based on information obtained from farm surveys, collection of news clippings, hospital and clinic-based surveillance, medical reports, or death certificate data (O'Connor, Gordon, \& Barnett, 1993; Gross, Peek-Asa, Ramirez, \& Gerr, 2012; Rissanen \& Taattola, 2003). A modern approach for accident information is from news clippings by searching in national and local newspapers (Ozegovic \& Voaklander, 2011; Pessina \& Facchinetti, 2017).

In the current analysis, Italian agriculture has been considered an interesting case study for tractor accidents due to the widespread use of tractors, the presence of many hilly lands, and the large number of arable crops, orchards, and vineyards. Injury data are traditionally provided by the Operational Archives of the Italian Workers Compensation Authority (INAIL), which collect injury reports of workers covered by compulsory accident insurance. They also include less severe injuries, so these records represent the wider source of non-fatal accident data. However, in June 1993, with Italian law 243/1993, self-employed people were excluded from compulsory insurance. Thereafter, INAIL considered only professional workers and there was a sharp decline of recorded data in the historical series. Indeed, between 1992 and 1994, a $40 \%$ reduction of injuries was recorded in agriculture together with 53\% fewer fatalities (INAIL, historical statistics). INAIL injury coding was then aligned to the ESAW approach. Nonetheless, given the variables describing causes and circumstances of accidents, obtaining detailed information about accident scenarios is rather difficult.

In 2002, an additional accident recording system was issued in Italy: the INAIL_ASL Surveillance System for fatal and severe work-related injuries. The database is managed by INAIL in cooperation with the Local Health Authorities (ASL), involving regions and autonomous provinces, with the coordination of the Ministry of Health. In archiving the accidents, a backward reconstruction process used in legal procedures is adopted. Factors leading to the accident and those influencing its sever- 137 ity are identified. Short narrative text reports describing fatalities and 138 some severe injuries are available online by consulting the Infor.MO 139 web tool. Even so, the main reconstructive descriptors of the accident 140 are sometimes lacking (Lombardi \& Rossi, 2013).

141

An INAIL Observatory project to add data and information on fatali- 142 ties in agriculture covering workers, even those not INAIL insured, was 143 then instituted in 2008. The Observatory collects accident data associ- 144 ated with the use of agricultural machinery; operational archives, 145 INAIL_ASL Surveillance System, newspapers and websites are the infor- 146 mation sources. Data from online newspapers and websites can reveal 147 injuries not detected by the traditional data reporting systems; 148 however, technical safety details are often omitted in news articles 149 and, moreover, the correctness of the information is not always 150 ascertainable.

The aim of the analysis in this article was to compare the tractor- 152 related fatalities data provided by the three official Italian reporting sys- 153 tems. This was done to characterize the rollover accidents scenario by 154 assessing the fitment on the tractor of the mandatory safety systems 155 (ROPS and driver seatbelts) and their correct use, the age of the victims, 156 and the contribution of environmental risk factors. The Italian data were 157 then compared with data available at an international level.

\section{Materials and methods}

Data of INAIL Operational Archives were provided by the statistical 160 service of INAIL (personal communication) and include 213 fatalities 161 in agriculture from 2002 to 2014. The Infor.MO web tool of the 162 INAIL_ASL Surveillance System was the second database analyzed for 163 data on fatal and severe work-related injuries. The website provides 164 short narrative text data for each recorded accident. Eight hundred 165 and seventeen fatalities were reported in agriculture from 2002 to 166 2012. These reports were analyzed to define the tractor rollover acci- 167 dent scenario. To identify the main cause of tractor-related accidents, 168 a text search method based on specific keywords (tractor, rollover, 169 overturn, ROPS, vehicle) was adopted. Fatalities due to tractor rollovers 170 were identified. The second step was studying additional elements 171 influencing the accident severity and its dynamics to identify the pres- 172 ence of ROPS and seatbelts, and specifying if these were mounted on 173 the tractor at the time of the accident, had been removed or were in 174 the folded-down position (Fig. 2).

However, given that the ROPS fitment was not always clearly stated, 176 in the current analysis the not specified ROPS rollover events were iden- 177 tified as "undefined." Therefore, a separate group of rollover accidents 178 related to the accident narrative texts lacking information regarding 179 the ROPS was considered. Concerning the driver restraint system as a 180 complement of the ROPS safety provision, most of the narrative reports 181 were absolutely vague on the fitment of a seatbelt system on the tractor. 182 Taking into consideration that, unfortunately, the requirement of the 183 seatbelt anchorage on the tractor is quite recent with respect to the 184 time period evaluated in the analysis, to show clear safety evidence it 185 was considered advisable to check if the driver was restrained by the 186 seatbelt. 
(a)

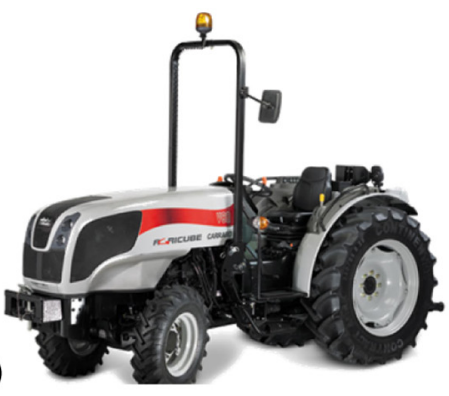

(b)

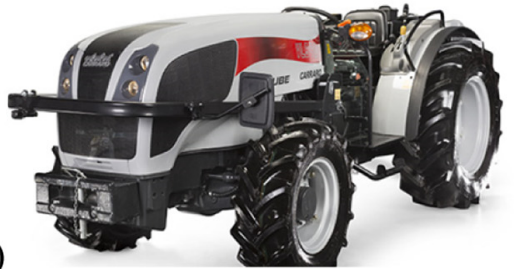

Fig. 2. Tractor fitted with a front foldable two post ROPS: (a) upright position of the ROPS providing for driver clearance zone, (b) inoperative ROPS in the folded-down position.

Since driver age is considered an important risk factor (Arana et al., 2010; Gross et al., 2012; O'Connor et al., 1993) tractor rollover fatalities were also divided between tractor drivers over 65 years old and those under 65 based on the driver age recorded by Surveillance System.

Lastly, environmental factors considered as relevant to the accident and reported by the Surveillance System were evaluated to better analyze the accident scenario. Main environmental factors in the database were: slippery soil (even for heavy rain or ice), steep embankment, steep slope, collapsed embankment, and deep ditches covered by thick vegetation.

The third accident database evaluated in the comparison was the INAIL Observatory from the period 2009-2014. Data were obtained by personal communications and official publications (INAIL, 2014, 2015) and were analyzed to distinguish tractor-related fatalities. However, the records did not allow details to be added on the definition of accident scenario.

\section{Results}

\subsection{Tractor-related fatalities overview}

INAIL Operational Archives for the period 2002-2014 reported 2007 fatalities in agriculture (on average, 154 per year), 213 were tractorrelated (10.6\%, 16 per year); however rollover events were not identifiable.

According to the data of the INAIL_ASL Surveillance System, in 20022012 there were 817 fatalities in agriculture (on average 74 per year) with 357 tractor-related ( 32 per year) and 205 tractor rollover fatalities (18 per year). Therefore, in this database tractor-related fatalities were $43.7 \%$ of total fatalities in agriculture, while rollover fatalities were $57.4 \%$ of tractor-related fatalities.

According to the INAIL Observatory, tractor-related fatalities for the period 2009-2014 were 766 (on average 128 per year), with 594 rollover fatalities (99 per year) representing $77.5 \%$ of tractor-related fatalities. Clearly the time considered for the three reporting systems differed. Nonetheless, a comparison of the yearly average of fatal injuries as recorded by the three reporting systems in the same observation time period (2009-2012) is shown in Fig. 3. There is an obvious difference in the data. The Surveillance System recorded a much lower number of fatalities in agriculture with respect to the Operational Archives (74 and 171, respectively). A possible explanation could be that the Operational Archives are compulsory and the notification of the accident is to obtain the insurance payment for the insured worker while the Surveillance System is based on data collected at regional level and the database could be affected by local procedures in providing accident details.

Considering the tractor effect on fatalities, according to the Surveillance System $43.7 \%$ of fatalities in agriculture were tractor-related (2002-2012), while the Operational Archives recorded only $10.6 \%$ (2002-2014). The Observatory gave many more tractor-related fatalities than the other two data sources; moreover, $43 \%$ of the victims were over 65 years old, a category of workers neglected by the
Operational Archives statistics. The crucial contribution of news clip- 237 pings for a more reliable evaluation of tractor fatalities is thus evident. 238

Data analyzed showed how the actual number of accidents in the 239 different reporting systems is clearly influenced by the database origin. 240 Without case matching, it could be totally inappropriate to mix data 241 from different sources to overcome the incompleteness of each data 242 set. Nevertheless, a thorough analysis of the different systems could 243 allow information from the various databases to be used as a stand- 244 alone source. The Operational Archives approach could be suitable for 245 comparing injuries and fatalities of professional workers to obtain in- 246 dexes representing farm workers, whereas poor information is provided 247 on accident dynamics and the vehicle involved. The Surveillance System 248 would be appropriate for investigating the causes and aggravating fac- 249 tors of fatalities because the short narrative text recording the accident 250 scenario allows the circumstances of the event to be defined, which may 251 allow appropriate measures to prevent accidents and/or their severity 252 to be identified. Indeed the added value of the database approach is re- 253 lated to the ASL staff inspecting the accidents, who are properly trained 254 to draft the accident text reports detailing the surrounding conditions, 255 aggravating factors, and incorrect behavior. However, a clear limitation 256 in the INAIL_ASL Surveillance System is the fewer accidents recorded 257 with respect to the INAIL Operational Archives. To improve the effi- 258 ciency of the system, a higher number of assigned operators would be 259 advisable. The INAIL Observatory system appears to be the most effec- 260 tive data source due to its ability to collect the largest number of tractor 261 fatalities, but the approach adopted made it difficult to compare their 262 data with the other sources and did not allow the event and surround- 263 ing conditions to be described in detail.

3.2. Accident scenario evaluation

Analysis of the narrative text recorded for tractor rollovers by the 266 INAIL_ASL Surveillance System allowed the dynamics of the accident 267

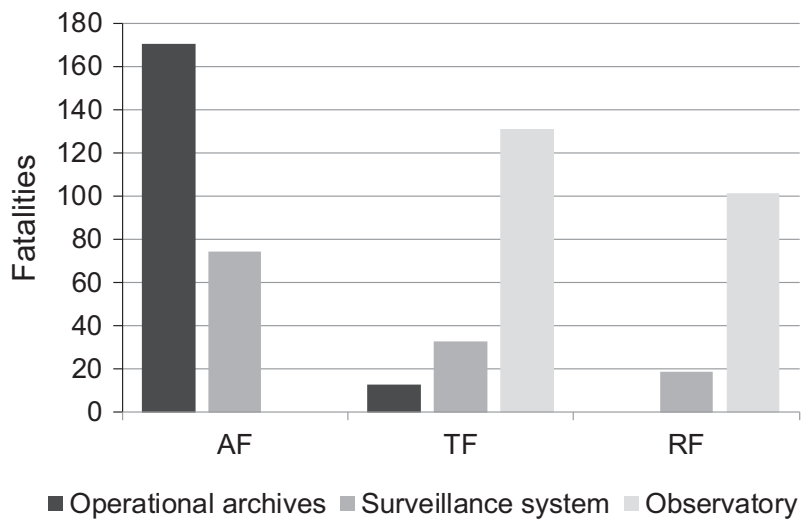

Fig. 3. Work-related fatalities in agriculture, yearly average (2009-2012), in the three Italian reporting systems. Total fatalities in agriculture (AF), tractor-related fatalities (TF), tractor rollover fatalities (RF). 
t1.1 Table 1

t1.2 Fatalities in Italian agriculture between 2002 and 2012, source Infor.MO web tool.

\begin{tabular}{lll}
\hline Fatalities & Frequency & $\%$ \\
\hline Tractor rollover & 205 & 25.1 \\
Fall from height & 124 & 15.2 \\
Hit by falling object & 88 & 10.8 \\
Change in the vehicle direction (rollover excluded) & 79 & 9.7 \\
Contact with objects, equipment or vehicles in motion & 78 & 9.5 \\
Accidental starting of the vehicle & 63 & 7.7 \\
Contact with moving parts & 69 & 8.4 \\
Projections of solids & 21 & 2.6 \\
Direct electrical contact & 19 & 2.3 \\
Other fatalities & 71 & 8.7 \\
Total & 817 & 100 \\
\hline
\end{tabular}

to be characterized, even though it should be noted that the information in the short reports was not homogeneous. Indeed, reports with a very detailed description of the accident scenario were available and narrative texts with very few details on the accident circumstances also existed.

Table 1 shows the main causes of fatalities in agriculture recorded for the period 2002-2012. Two hundred and five tractor rollovers fatalities were recorded. An evaluation of the accident text reports was done concerning the safety systems mounted on the tractors at the time of the accident.

Concerning the driver seatbelts, few narrative texts highlighted the fitment of the seatbelt anchorage on the driver seat. Very few reports did note that the driver was not restrained during the rollover event but there were no reports that referred to the driver being restrained at the time of the accident. Consequently, it was assumed that in the 205 rollover fatalities, the drivers were not fastened in during the event, and therefore the information on seatbelt was not included in tables and figures. This approach was also supported by the fact that it is estimated that only $23 \%$ of the 1.5 million tractors in use in Italy are mounted with a driver restraint system (Italian Senato Resolution, 2015).

ROPS fitment on the tractors involved in fatal rollover accidents with respect to the activity performed, for example, in field operations or in transport on farm or public roads, for workers under and over 65 years old is depicted in Table 2 . The results showed that ROPS fitment is a discriminant factor on the outcome of the overturning: 71.7\% ( $n=$ 147) of the fatal accidents were related to tractors without ROPS, $18 \%$ $(n=37)$ to ROPS equipped tractors and $10.2 \%(n=21)$ to the notspecified category. Nevertheless, by assuming this category as part of the ROPS equipped tractors the percentage would increase to $28.2 \%$ of fatalities.

Analyzing data for both driver age and ROPS fitment, $42.4 \%$ of fatal accidents involved workers over 65 , and these were driving tractors without ROPS in $78.2 \%$ of the rollover events. Only $12.6 \%$ of the accidents pertained to ROPS equipped tractors (Fig. 4). The percentage of over 65 driving non-ROPS equipped tractors (78.2\%) was, as expected, higher than the percentage of other workers (66.9\%).

$52.2 \%$ of fatalities occurred in normal field operations while $42.9 \%$ referred to the tractor in operation or while being driven on the farm or on

Table 2 a public road. The ROPS fitment in field and road accidents were sub- 307 stantially equivalent, $71.9 \%$ of tractors were non-ROPS equipped in 308 field operations with respect to the $71.6 \%$ on the road 309

The fatalities attributed to no ROPS tractors $(n=147)$ were evalu- 310 ated to verify if the tractors were manufactured without ROPS or if the 311 ROPS was originally installed but had been removed or was in the 312 folded-down position (Fig. 2) at the time of the accident, as frequently 313 observed when narrow track tractors are used in the field (Khorsandi, 314 Ayers, Jackson, \& Wilkerson, 2016). The data were recorded according 315 to the activity performed for both worker groups (Table 3 ).

$73.5 \%$ of fatalities involved tractors without a ROPS protection origi- 317 nally installed by the manufacturer, $21.8 \%$ of fatalities were related to 318 tractors with foldable ROPS with the ROPS in the folded-down position 319 (equivalent to no ROPS protection for the driver), and lastly, $4.8 \%$ of fatal 320 accidents concerned tractors with foldable ROPS but the ROPS had been 321 removed at the time of the event (Fig. 5)

Considering the fatalities related to worker age, the percentage of 323 tractors without ROPS involved in fatal rollovers was $25.2 \%$ higher for 324 the over 65 age group ( 82.4 and $65.8 \%$ for the over and under 65 years 325 old workers, respectively). Taking into consideration the tractors 326 equipped with foldable ROPS in the folded-down position at the time 327 of rollover, the percentage of fatalities for drivers under 65 years old is 328 almost double that involving drivers over 65 (27.8\% and $14.7 \%, 329$ respectively).

Considering activities, for the tractor in field operations the fatalities 331 involving no ROPS tractors were $66.2 \%$ while they were $82.5 \%$ for the 332 tractor in operation or while being driven on the farm or on a public 333 road. The ROPS was in the folded-down position in $28.6 \%$ of field events 334 and in $12.7 \%$ of those on the road. This is consistent with the fact that 335 when working in the field, the upright position of the ROPS could affect 336 performing the operation correctly; that is why narrow track tractors 337 are mounted with front foldable, two post ROPS allowing a folded- 338 down position when the space for the tractor is restricted by the crop, 339 as in orchard or vineyard inter-rows. Nevertheless, the fatalities re- 340 corded during road operation clearly do not involve this need and de- 341 note an incorrect use of the tractor.

Analyzing the fatal rollovers to ROPS equipped tractors ( $n=37$ ), for 343 which an acceptable level of protection for the driver could be expected, 344 the fatal outcome was due to the lack of retention of the driver inside 345 the clearance zone. It was clearly stated in the narrative report that 346 the driver was thrown out of the driver seat and/or repeatedly bumped 347 into the ROPS frame. More precisely, $37.8 \%$ of deaths $(n=14)$ were be- 348 cause the driver was crushed by the tractor on impact with the ground, 349 while in $24.3 \%$ ( $n=9$ ) of the cases, the driver hit the ROPS. One fatal 350 event $(2.7 \%)$ was because the driver drowned while trapped inside 351 the ROPS cab, and in one case (2.7\%) the driver was crushed in the col- 352 lapsed ROPS cab. In the remaining rollover events, 32.4\% $(n=12)$, the 353 accident narrative texts did not detail the cause of the fatalities. The lit- 354 erature suggest a collapsed ROPS is very rare in agricultural operations 355 (Reynolds \& Groves, 2000; Pessina \& Facchinetti, 2017) and our analysis 356 supports this.

Tractor rollover fatalities where environmental factors clearly con- 358 tributed to the accident were $16.6 \%$ of the recorded accidents $(n=359$ $34)$. The most frequent causes of overturning were due to the presence 360

Fatal tractor rollovers with respect to ROPS fitment, tractor activity and driver age (205 accidents, from 2002 to 2012 ).

\begin{tabular}{|c|c|c|c|c|c|c|c|c|c|}
\hline & \multicolumn{3}{|l|}{ Total } & \multicolumn{3}{|c|}{ Over 65 years } & \multicolumn{3}{|c|}{ Under 65 years } \\
\hline & In field & In transfer & Undefined & In field & In transfer & $\overline{\text { Undefined }}$ & In field & In transfer & $\overline{\text { Undefined }}$ \\
\hline ROPS & 21 & 15 & 1 & 5 & 6 & 0 & 16 & 9 & 1 \\
\hline No ROPS & 77 & 63 & 7 & 34 & 29 & 5 & 43 & 34 & 2 \\
\hline Undefined & 9 & 10 & 2 & 4 & 4 & 0 & 5 & 6 & 2 \\
\hline Total & 107 & 88 & 10 & 43 & 39 & 5 & 64 & 49 & 5 \\
\hline
\end{tabular}

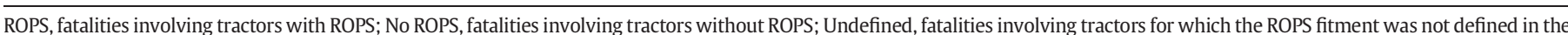
records. 


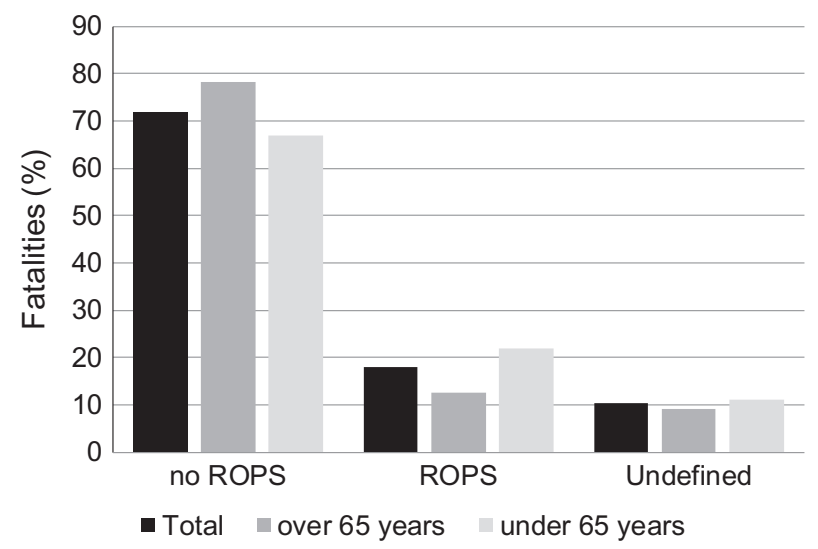

Fig. 4. Tractor fatalities (\%) related to worker age (over and under 65 years) and ROPS installation. Tractors non-ROPS equipped (no ROPS); Tractors with ROPS (ROPS); ROPS not assessed (Undefined).

of slopes, ditches, or embankments (27\%), an excessive or unbalanced load on the tractor (16.2\%) and mechanical problems (8.1\%). In field operations the main environmental contributions were tractors sliding into ditches or bumping against obstacles, sometimes not visible, and tractors working on slopes or slippery ground. In tractors driving on roadways, the main environmental factors involved were the lack of road maintenance and steep slopes adjacent to the tractor path. As already reported, the tractor rollover accident occurrence is frequently affected by environmental risk factors (Arana et al., 2010; Degroot, Isaacs, Pickett, and Brison, 2011).

\section{Discussion}

Fatal and non-fatal tractor injury are often difficult to compare among different countries because the injury rates are related to the approach and the objective of the data source. Traditional reporting systems often refer only to insured workers, thus accounting for just a proportion of the actual victims of accidents in agriculture (Franklin, Mitchell, Driscoll, \& Fragar; 2000; Mayrhofer, Quendler, \& Boxberger, 2013). The underestimation of fatal accidents by data sources related to occupational injuries is quite common in the reporting systems of many countries (Arana et al., 2010; Murphy \& Yoder, 1998). In the current data analysis the average annual number of tractor-related fatal accidents recorded by the INAIL Operational Archives was only $41 \%$ of that recorded by the INAIL_ASL Surveillance System, while the value reported by the INAIL Observatory is, respectively, 4 and 10 times higher than the Surveillance System and Operational Archives data.

In the literature, tractor-related fatalities recorded in agriculture are quite consistent with the data of the Italian Surveillance System: 43.7\% of total farm fatalities were tractor fatalities, as depicted in Table 4 that shows an international overview of the tractor accident rate. Day (1999) refers to a higher percentage (72\% from 1985 to 1996) based on data obtained by the Workcover Authority Health and Safety

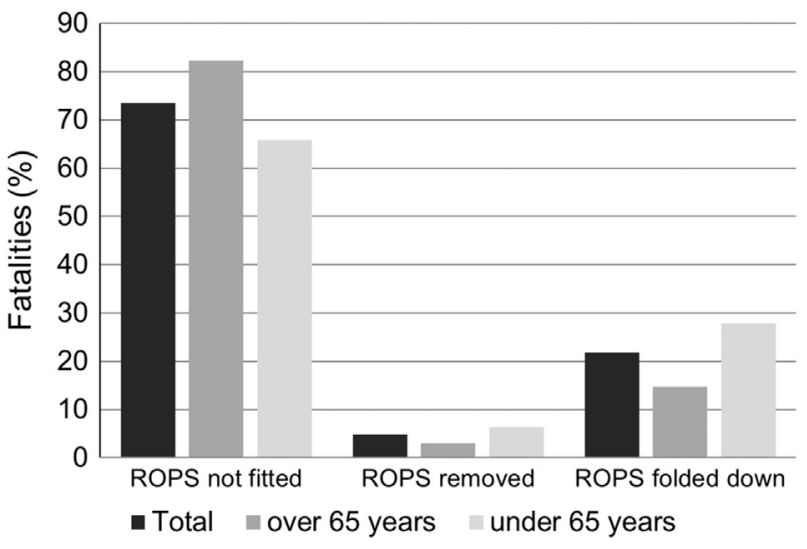

Fig. 5. Fatalities related to tractor rollovers without ROPS protection with respect to driver age. Tractors non-ROPS equipped (ROPS not fitted); tractors manufactured with foldable ROPS but ROPS was removed (ROPS removed); tractors manufactured with foldable ROPS and the ROPS was in the inoperative folded-down position (ROPS folded down).

Division of the state of Victoria, Australia; while Jones, Day, and 393 Staines (2013), based on the same data source, propose a lower percent- Q6 age (56.5\%) because a longer period of time was considered, including 395 more recent data (1985-2010) denoting a significant decrease of the re- 396 corded tractor fatalities in the more recent years; this may be due to the 397 increase of ROPS equipped tractors. For the period 2000-2010, tractor 398 fatalities were $46 \%$ of farm fatalities, a result consistent with data 399 shown in the present study (Table 4).

Based on the INAIL_ASL Surveillance System, 25.1\% of fatalities in 401 agriculture and $57.4 \%$ of tractor fatalities were due to a rollover 402 event, which is data consistent with the international literature 403 (Table 4). According to Bunn et al. (2008), data from the Kentucky 404 Fatality Assessment and Control Evaluation (FACE), rollover fatalities 405 were about half of total tractor fatalities, a value similar to the 406 $57.4 \%$ reported in the present study. Arana et al. (2010) showed a 407 higher value (70.1\%) for Spanish agriculture in 2004-2008, basing 408 their analysis on 388 fatal accidents recorded in newspaper articles 409 and from an internet search.

The performance of the ROPS protection in tractor rollover is widely 411 documented in the literature (Browning, Westneat, Truszczynska, Reed, 412 \& McKnight, 1995; Kelsey, May, \& Jenkins, 1996; Reynolds \& Groves, 413 2000; Myers, Cole, \& Westneat, 2008; Jones et al., 2013). Springfeldt 414 et al. (1998) verified a 93\% reduction of rollover fatalities in Sweden, 415 from 12 to 0.2 fatalities per 100,000 tractors over 30 years, with ROPS 416 equipped tractors increasing from 6 to 93\% in the period 1957-1990. 417 The incidence of non-ROPS equipped tractors in many countries is esti- 418 mated (NHIOSH, 2010; INSHT, 2009; MAPA, 2006; Cole, 2003; Hoy, 419 2009; Loringer \& Myers, 2008); this is not the case for Italy because of- 420 ficial data are not available. Nonetheless, tractor ROPS fitment has the 421 aim of minimizing the risks for the driver; therefore the potential fatal 422 outcome in the case of a rollover event is not excluded. In the current 423 study, the fatalities with ROPS equipped tractors were $18 \%$ of total roll- 424 over fatalities; in just one case the ROPS collapsed; in almost all these 425

Table 3

Fatal tractor rollovers with respect to ROPS fitment, tractor activity and driver age (147 accidents, 2002-2012).

\begin{tabular}{|c|c|c|c|c|c|c|c|c|}
\hline & \multicolumn{3}{|l|}{ Total } & \multicolumn{3}{|c|}{ Over 65 years } & \multicolumn{2}{|c|}{ Under 65 years } \\
\hline & In field & In transfer & Undefined & In field & In transfer & Undefined & In transfer & Undefined \\
\hline Not fitted & 51 & 52 & 5 & 26 & 26 & 4 & 26 & 1 \\
\hline Uninstalled & 4 & 3 & 0 & 1 & 1 & 0 & 2 & 0 \\
\hline Folded down & 22 & 8 & 2 & 7 & 2 & 1 & 6 & 1 \\
\hline Total & 77 & 63 & 7 & 34 & 29 & 5 & 34 & 2 \\
\hline
\end{tabular}

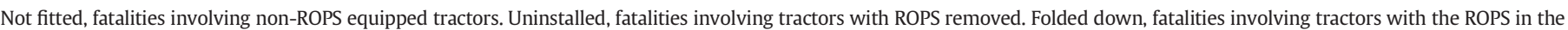
inoperative folded-down position. 
t4.1 Table 4

t4.2 Tractor accidents rate, an international overview.

t4.3

\begin{tabular}{lll}
\hline Reference & Rate Country & $\begin{array}{l}\text { Data } \\
\text { source } \\
\text { years }\end{array}$ \\
& \\
\hline
\end{tabular}

Tractor fatalities with respect to total fatalities in agriculture (\%)

48 Kentucky, USA 1994-2005

Day, 1999

Jones et al., 2013

Murphy and Yoder, 1998

NHIOS, 2010

Pickett, Hartling, Brison, and Guernsey,

1999

Present study ${ }^{\mathrm{a}}$

Present study

48 Kentucky,
72 Victoria,

Australia

56.5 Victoria,

Australia

32.1 USA

36 USA

47.5 Canada

1985-1996

1985-2010

1992-1995

2003-2007

1991-1995

10.6 Italy 2002-2014

43.7 Italy 2000-2012

Tractor rollover fatalities with respect to total fatalities in agriculture (\%)

DeGroot et al., $2011 \quad 20.4$ Canada $1990-2005$

Jones et al., $2013 \quad 23.7$ Victoria, $1985-2010$

$\begin{array}{llll} & \text { Australia } & \\ \text { NHIOSH, } 2010 & 16.4 & \text { USA } & 2003-2007\end{array}$

$\begin{array}{lll}\text { Present study }^{\mathrm{b}} & 25.1 & \text { Italy 2002-2012 }\end{array}$

Tractor rollover fatalities with respect to total tractor fatalities (\%)

Arana et al., 2010

70.1 Spain

Bunn et al., 2008

Day, 1999

52.2 Kentucky, USA

61 Victoria,

Australia

Dogan et al., 2010

Jones et al., 2013

NHIOSH, 2010

Present study

37.2 Turkey, Konya

42.0 Victoria,

Australia

45.2 USA

57.4 Italy

2004-2008

1994-2004

1985-1996

2000-2007

1985-2010

2003-2007

2002-2012

Rollover fatalities referred to ROPS equipped tractors with respect to total rollover fatalities (\%)

Arana et al., 2010

Day, 1999

Myers et al., 2009

Present study

0.4 Spain

17 Victoria,

Australia

2004-2008

Kentucky, USA 2002

Authors' elaboration based on

a INAIL, Operational Archives

b INAIL_ASL Surveillance System

cases the driver not wearing the seatbelt did not remain protected inside the ROPS clearance zone.

The percentage of fatalities with ROPS equipped tractors is significantly higher than the values reported by other authors. Myers et al. (2009) noted $4 \%$ of fatalities in rollover accidents involving ROPS fitted tractors; Arana et al. (2010) evaluated 272 fatal overturns and only one involved a ROPS equipped tractor; Day (1999) showed a higher percentage, $17 \%$, close to the value obtained from the Italian Surveillance System (Table 4).

In relation to the age of the driver involved in fatalities the international literature shows that in agriculture the frequency of the elderly is higher than in the other fatalities (Table 5). The percentage of elderly victims ranged between 20 and $40 \%$ in agriculture while the data of the Italian INAIL Operational Archives showed a percentage of $17 \%$. As already mentioned, the gap could be due to the fact that the elderly population is generally not insured and is therefore not recorded in the archives. Concerning tractor fatalities, the percentage of elderly victims in the literature is generally higher than those of the INAIL Operational Archives while the INAIL_ASL Surveillance System refers to data more in line with the international statistics. The low rate documented by Dogan et al. (2010) could be related to the fewer ROPS equipped tractors in Turkey, as evidenced by Cavallo et al. (2014), which aligns the risk conditions of all drivers independently of age and working operations. Arana et al. (2010) explained the higher risk of death, increasing with driver age, by hypothesizing that elderly people drive older, non-ROPS equipped tractors.
In Italy, as in many European countries, complete workers compen- 453 sation archives and complementary monitoring systems are the refer- 454 ence databases for workplace injuries and fatalities. Considerable 455 differences emerge in the accident data according to the reporting sys- 456 tem considered. Many official accident archives consider only insured 457 workers. As a consequence, injuries involving categories such as self- 458 employed, retired, and part-time workers or unpaid family members, 459 are in many instances not recorded causing a huge lack of information 460 in agriculture.

461

Tractor-related fatalities in Italian agriculture range from 10.6 to 462 $43.7 \%$, depending on the data source. Total average number of tractor 463 fatalities per year ranged from 16 to 128 for the INAIL Operational 464 Archives and INAIL Observatory, respectively. The INAIL Observatory 465 data source probably provides the most reliable number of tractor- 466 related fatalities with respect to the other two Italian data sources. Nev- 467 ertheless, despite its incompleteness, data of the INAIL_ASLSurveillance 468 System, which has short narrative text reports, provides information on 469 accident scenarios.

470

Regarding the tractors involved in fatalities, $71.7 \%$ of the fatal 471 tractor-related accidents involved non-ROPS equipped vehicles. 472 Concerning tractors manufactured with a ROPS protection, a result 473 worth highlighting is the high number of tractor rollover fatalities asso- 474 ciated with tractors equipped with front foldable ROPS in the inopera- 475 tive folded-down position (21.8\%) or even removed (4.8\%) during the 476 rollover event.

477

Nonetheless, the ROPS fitment did not guarantee the protection of 478 the driver in all overturning situations; indeed 18\% of rollover fatalities 479 concerned ROPS equipped tractors. In this respect, it should be 480 underlined that an additional $10.2 \%$ of tractor-related fatalities was un- 481 certain because the ROPS fitment was not clearly stated in the reports, 482 so that percentage was not categorized. Data recorded for ROPS 483 equipped vehicles included just one fatality associated with the ROPS 484 collapsing on impact with the ground, confirming the very positive per- 485 formance of the ROPS in rollovers. In ROPS equipped tractors, the main 486 cause of fatalities was the driver being thrown outside the clearance 487 zone, crushed beneath the tractor, or colliding with the ROPS mount- 488 ings, because the victim was not restrained in the seat. As already stated 489 in the international literature (Day, 1999; Molari \& Rondelli, 2007; 490 Myers \& Pana-Cryan, 2000) the seatbelt is confirmed as a necessary 491 safety component for effective ROPS performance. No records denoted 492 the use of the driver restraint system at the time of the accident. Fatal 493 accidents were often associated with an inadequate perception of the 494 rollover risk, mainly on sloping or slippery areas and/or in the presence 495

Table 5

Elderly fatalities rate, an international overview.

t5.1

Reference Country

Fatalities for elderly workers with respect to total agriculture fatalities (\%)

$\begin{array}{lllll}\text { Gross et al., } 2012 & 30.7 & \text { USA } & 2011 & \text { t5.5 }\end{array}$

$\begin{array}{lllll}\text { NHIOS, } 2010 & 40 & \text { USA } & \text { 2003-2007 } & \text { t5.6 }\end{array}$

Pickett et al., 1999

Present study ${ }^{\mathrm{a}}$

$\begin{array}{llll} & 17 & \text { Italy } & 2002-2014\end{array}$

Tractor fatalities for elderly workers with respect to total tractor fatalities (\%)

Arana et al., 2010

DeGroot et al., 2011

Gross et al., 2012

Pickett et al., 1999

Present study ${ }^{\mathrm{a}}$

Present study ${ }^{\mathrm{b}}$

Rissanen \& Taattola, 2003

44.6 Spain 2004-2008

43.6 Canada 1990-2005

40 USA 2011

46.7 Canada 1991-1995

22 Italy 2002-2014

$42.4 \quad$ Italy 2002-2012

Authors' elaboration based on

Finland 1988-2000

$\mathrm{t} 5.6$
$\mathrm{t} 5.7$

t5.8

t5.9

$\mathrm{t} 5.10$
$\mathrm{t} 5.11$

t5.12

t5.13

t5.14

t5.15

t5.16

t5.17

t5.18

a INAIL Operational Archives and

b INAIL_ASL Surveillance System 
of obstacles. Concerning the age of the victims in tractor rollovers, the percentage of elderly was higher for the non-ROPS equipped tractors.

As a general conclusion it should be highlighted that the approach adopted by the INAIL_ASL Surveillance System based on data with short narrative text was shown to be highly advantageous for characterizing the accident scenario. Although the recorded events underestimated the number of tractor-associated fatalities, its value is due to the rigorous method adopted in accident reporting. Unfortunately, the data source did not record non-fatal cases nor information deriving from farmer's surveys or hospital reports. Nevertheless, this costly and time-consuming approach could allow public prevention policies to be defined, such as massive training campaigns among farmers on the correct use of ROPS equipped tractors. This approach could also help researchers and tractor manufacturers enhance the effectiveness of ROPS on modern tractors. Additionally, a strict requirement to retrofit ROPS on all tractors could increase the survival chances of drivers in rollover accidents.

\section{Funding}

This research did not receive any specific grant from funding agencies in the public, commercial, or not-for-profit sectors.

\section{Uncited references}

EC, 2003

Italian Legislative, 2008

\section{Acknowledgements}

The authors acknowledge the National Institute for Insurance against Accidents at Work, for the statistics and accidents information provided.

\section{References}

Arana, I., Mangado, J., Arnal, P., Arazuri, S., Alfaro, J. R., \& Jarén, C. (2010). Evaluation of risk factors in fatal accidents in agriculture. Spanish Journal of Agricultural Research, 8(3), 592-598.

Arndt, J. F. (1971). Roll-over protective structures for farm and construction tractors-a 50-year review. SAE Technical Paper Series, Vol. 710508. Warrendale, PA.

Browning, S. R., Westneat, S. C., Truszczynska, H., Reed, D., \& McKnight, R. (1995). Farm tractor safety in Kentucky. Public Health Reports, 114, 53-59.

Bunn, T. L., Slavova, S., \& Hall, L. (2008). Narrative text analysis of Kentucky tractor fatality reports. Accident Analysis and Prevention, 40(2), 419-425.

Cavallo, E., Langle, T., Bueno, D., Tsukamoto, S., Görücü, S., \& Murphy, D. (2014). Rollover protective structure (ROPS) retrofitting on agricultural tractors: Goals and approaches in different countries. Journal of Agromedicine, 19(2), 208-209.

Cole, H. P. (2003). Farmers' perceptions of ROPS and tractor safety: Studies, stories, and statistics. Record of Tractor-related Injury and Death Meeting, Pittsburgh, PA, February 13-14 (pp. 217-218). Morgantown, WV: NIOSH.

Day, L. (1999). Farm work related fatalities among adults in Victoria, Australia: the human cost of agriculture. Accident; Analysis and Prevention, 31, 153-159.

Day, L., Rechnitzer, G. \& Lough, J. (2004). An Australian experience with tractor rollover protective structure rebate programs: Process, impact and outcome evaluation. Accident Analysis \& Prevention, 36(5), 861-867.

Degroot, J. M., Isaacs, C., Pickett, W., \& Brison, R. J. (2011). Patterns of fatal machine rollovers in Canadian agriculture. Chronic Diseases and Injuries in Canada, 31(3), 97-102.

Dogan, K. H., Demirci, S., Sunam, G. S., Deniz, I., \& Gunaydin, G. (2010). Evaluation of farm tractor-related fatalities. American Journal of Forensic Medicine and Pathology, 31(1) 64-68.

EC (1974). Directive 74/150/EEC on tractors and agricultural or forestry machinery: Approximation of the laws. Available at www.eur-lex.eu.

EC (2003). Directive 2003/37/EC on type-approval of agricultural or forestry tractors, their trailers, and interchangeable towed machinery, together with their system, components, and separate technical units. Available at www.eur-lex.eu.

EC (2005). Directive 2005/67/EC on adapting the type-approval of agricultural or forestry tractors. Available at www.eur-lex.eu.

Franklin, R., Mitchell, R., Driscoll, T., \& Fragar, L. (2000). Farm-Related Fatalities in Australia, 1989-1992. Moree: Australian Centre for Agricultural Health and Safety (ACAHS), National Occupational Health and Safety Commission (NOHSC), Rural Industries Research and Development Corporation (RIRDC).

Gross, N., Peek-Asa, P., Ramirez, M., \& Gerr, F. (2012). Agriculture-related fatalities reported through newspapers in nine Midwest States. Available at http://www.publichealth. uiowa.edu/gpcah/publications/Ag_Surveillance_Report_11dec12.pdf.
Guzzomi, A. L., Rondelli, V., Guarnieri, A., Molari, G., \& Molari, P. G. (2009). Available en- 563 ergy in the rollover of narrow track wheeled agricultural tractors. Journal of 564 Biosystems Engineering, 104(3), 318-323.

Harald, A., \& Moberg, S. (1973). Dynamic Testing of Tractor Protection Cabs-Development of 566 Method, Practical Experiences. No. 730761. SAE Technical Paper. 567

Hoy, R. M. (2009). Farm tractor rollover protection: Why simply getting rollover protec- 568 tive structures installed on all tractors is not sufficient. Journal of Agricultural Safety 569 and Health, 15, 3-4.

INAIL (2014). Report annuale sugli infortuni mortali e con feriti gravi verificatisi nel 2013 nel 571 settore agricolo e forestale. Available at https://www.inail.it/cs/internet/comunicaz 572 ione/news-ed-eventi/.

INAIL (2015). Report annuale sugli infortuni mortali e con feriti gravi verificatisi nel 2014 nel 574 settore agricolo e forestale. Available at https://www.inail.it/cs/internet/comunicaz 575 ione/news-ed-eventi/.

Instituto Nacional de Seguridad e Higiene en el Trabajo (INSHT) (2009). Encuesta Nacional 577 de Condiciones de Trabajo en el Sector Agropecuario. Available at http://www.insht.es/ 578 Observatorio/Contenidos/InformesPropios/Desarrollados/Ficheros/Encuesta\%20Na 579 cional\%20Agropecuaria.pdf.

Italian Legislative (2008). Decree no. 81 of 9 April 2008. Safety Consolidation Act. Imple- 581 mentation of Article 1 of Law no. 123 of 3 August 2007 on the protection of health 582 and safety at work. Journal of the Italian Republic, 101(Ordinary Supplement) Apr 583 30. Italian.

Italian Workers' Compensation Authority, INAIL, Infor.Mo web site. Available at: https://a 585 ppsricercascientifica.inail.it/getinf_u/selinf.asp 586

Italian Workers' Compensation Authority, INAIL, historical statistics. Available at: https:// 587 www.inailit/cs/internet/attivita/dati-e-statistiche/statistiche-storiche/casi-denuncia 588 ti-e-indennizzati.html

Jawa, R. S., Young, D. H., Stothert, J. C., Yetter, D., Dumond, R., Shostrom, V. K., ... Mercer, D. 590 W. (2013). Farm machinery injuries: The 15-year experience at an urban joint 591 trauma center system in a rural state. Journal of Agromedicine, 18(2), 98-106. 592

Jones, C. B., Day, L., \& Staines, C. (2013). Trends in tractor related fatalities among adults 593 working on farms in Victoria, Australia, 1985-2010. Accident Analysis \& Prevention, 594 $50,110-114$

Kelsey, T. W., May, J. J., \& Jenkins, P. L. (1996). Farm tractors, and the use of seat 596 belts and roll-over protective structures. American Journal of Industrial Medicine, 597 30, 447-451.

Khorsandi, F., Ayers, P. D., Jackson, D. L., \& Wilkerson, J. (2016). The effect of speed 599 on foldable ROPS actuation forces. Journal of Agricultural Safety and Health, 22600 (4), 285-298.

Kogler, R., Quendler, E., \& Boxberger, J. (2015). Analysis of occupational accidents 602 with agricultural machinery in the period 2008-2010 in Austria. Safety Science, 603 72, 319-328.

Legislative Decree on Safety at Work (2008). Italian Ministry of Labour and Social Secu- 605 rity: Legislative Decree $\mathrm{n} 81$ of 9th April 2008. Official Journal, 101 of 30th April. 606

Lombardi, M., \& Rossi, G. (2013). Cluster analysis of fatal accidents series in the INFOR. MO 607 database: Analysis, evidence and research perspectives. International Journal of Safety 608 and Security Engineering, 3(4), 317-331.

Loringer, K. A., \& Myers, J. R. (2008). Tracking the prevalence of rollover protective struc- 610 tures on U.S. farm tractors: 1993, 2001, and 2004. Journal of Safety Research, 39(5), 611 509-517.

Marshall, S. W., Clarke, J., Langley, J. D., \& Cryer, P. C. (1996). Overview of injury on New 613 Zealand farms. Journal of Agricultural Safety and Health, 2(4), 175-190. 614

Mayrhofer, H., Quendler, E., \& Boxberger, J. (2013). Occupational incidents with self- 615 propelled machinery in Austrian agriculture. Journal of Agromedicine, 18(4), 359-367. 616

Mayrhofer, H., Quendler, E., \& Boxberger, J. (2014). Narrative text analysis of accident re- 617 ports with tractors, self-propelled harvesting machinery and materials handling ma- 618 chinery in Austrian agriculture from 2008 to 2010 - A comparison. Annals of 619 Agricultural and Environmental Medicine, 21(1), 183-188.

Ministerio De Agricultura, Pesca y Alimentación, MAPA, Spain. Análisis del Parque 621 Nacional de Tractors Agrícolas 2005-2006. Available at: http://www.magrama.gob. 622 es/es/agricultura/publicaciones/parque_tractores_tcm7-1122.pdf 623

Molari, G., \& Rondelli, V. (2007). Evaluation criteria for the anchorage resistance of safety 624 belts on agricultural tractors. Biosystems Engineering, 97(2), 163-169. 625

Murphy, D., \& Yoder, A. M. (1998). Census of fatal occupational injury in the agriculture, 626 forestry, and fishing industry. Journal of Agricultural Safety and Health Special Issue, 1, 627 55-66.

Myers, J. R. (2010). Factors associated with the prevalence of non-ROPS tractors on farms 629 in the US. Journal of Agricultural Safety and Health, 16(4), 265-278.

Myers, J. R., Synder, K. A., Hard, D. L., Casini, V. J., Cianfrocco, R., Fields, J., \& Morton, L. 631 (1998). Statistics and epidemiology of tractor fatalities - A historical perspective. 632 Journal of Agricultural Safety and Health, 4(2), 95-108.

Myers, M., Cole, H., \& Westneat, S. (2008). Projected incidence and cost of tractor 634 overturn-related injuries in the United States. Journal of Agricultural Safety and 635 Health, 14(1), 93-103.

Myers, M. L. (2000). Prevention effectiveness of rollover protective structures-Part I: 637 Strategy evolution. Journal of Agricultural Safety and Health, 6(1), 29-40. 638

Myers, M. L., Cole, H. P., \& Westneat, S. C. (2009). Injury severity related to overturn char- 639 acteristics of tractors. Journal of Safety Research, 40(2), 165-170. 640

Myers, M. L., \& Pana-Cryan, R. (2000). Prevention effectiveness of rollover protective 641 structures-Part II: Decision analysis. Journal of Agricultural Safety and Health, 6(1), 642 41-55.

NHIOS, The National Institute for Occupational Safety and Health, Occupational Injury 644 Surveillance of Production Agriculture available at: https://www.cdc.gov/niosh/ 645 topics/aginjury/oispa/techinfo.html

O'Connor, T. A., Gordon, J. E. \& Barnett, M. (1993). Agricultural injury surveillance using a 647 state injury registry. Journal of Safety Research, 24, 155-166. 648 
Ozegovic, D., \& Voaklander, D. C. (2011). What we are not talking about: An evaluation of prevention messaging in print media reporting on agricultural injuries and fatalities. American Journal of Industrial Medicine, 54(8), 603-608.

Pessina, D., \& Facchinetti, D. (2017). A survey on Fatal Accidents for Overturning of Agricultural Tractors in Italy. Chemical Engineering Transactions, 58, 79-84.

Pickett, W., Hartling, L., Brison, R. J., \& Guernsey, J. R. (1999). Fatal work-related farm injuries in Canada, 1991-1995. Canadian Medical Association Journal, 160(13), 1843-1848.

Reynolds, S. J., \& Groves, W. (2000). Effectiveness of rollover protective structures in reducing farm tractor fatalities. American Journal of Preventive Medicine, 18, 63-69.

Rissanen, P., \& Taattola, K. (2003). Fatal injuries in Finnish agriculture, 1988-2000. Journal of Agricultural Safety and Health, 9, 319-326.

Sanderson, W. T., Madsen, M. D., Rautiainen, R., Kelly, K. M., Zwerling, C., Taylor, C. D., ... Merchant, J. A. (2006). Tractor overturn concerns on Iowa: Perspectives from the Keokuk county rural health study. Journal of Agricultural Safety and Health, 12(1), 71-81.

Senato della Repubblica (2015). Risoluzione della 9 ${ }^{\underline{a}}$ Commissione Permanente, Agricoltura e produzione agroalimentare, Doc. XXIV n. 48, 13 maggio. Available at http://www.sena to.it/service/PDF/PDFServer/BGT/916936.pdf.

Springfeldt, B. (1996). Rollovers of tractors - International experiences. Safety Science, 24 (2), 95-110.

Springfeldt, B., Thorson, J., \& Lee, B. C. (1998). Sweden's thirty-year experience with tractor rollovers. Journal of Agricultural Safety and Health, 4(3), 173-180.

Tinc, P. J., Ayers, P. D., May, J. J., Purschwitz, M. A., \& Sorensen, J. A. (2015). Creating a national coalition to address tractor overturn fatalities. Journal of Agricultural Safety and Health, 21(2), 105-112.
Valda Rondelli earned her degree in Agricultural Science, from Faculty of Agriculture, 673 University of Bologna, (First class honours, 1987). She earned her Doctorate in Agri- 674 cultural Mechanisation from University of Bologna. She has been a Researcher at 675 the University of Bologna, Department of Agricultural and Food Sciences (DISTAL) 676 since October 1999. She has been as head of the Laboratorio di Meccanica Agraria 677 of the DISTAL, official OECD Testing Station for tractor performance and ROPS 678 strength since December 2008. She is an Associate Professor at the University of Bo- 679 logna, Department of Agricultural and Food Sciences (DISTAL) since September 2014. 680

Camilla Casazza earned her degree in Materials Engineering from University of Ferrara. 682 She earned her PhD in Agricultural Engineering from University of Bologna. Her areas of 683 experience include experience in the materials quality, performance evaluations, Risk 684 Analysis and homologation of agricultural Machinery He collaborated with CNR_ 685 Imamoter and Laboratorio di Meccanica Agraria, OECD TEST Station, Department of Agri- 686 cultural and Food Sciences of the University of Bologna.

Roberta Martelli has been an Adjunct Professor of the University of Bologna and the 689 University of Modena and Reggio Emilia. She carries out his research in the field of 690 Mechanical Engineering and agricultural mechanization. Research interests are partic- 691 ularly focused on integrated mechanical solutions for organic farming; qualitative as- 692 pects of vegetables connected with mechanical harvesting; harvest mechanization of 693 energy Crops; physical-mechanical properties of vegetables during storage; Precision Agriculture; viticulture innovative equipment. She is the Author of about a hundred publications. 